\title{
Stigmatic Receptivity Limits The Effective Pollination Period In Kiwifruit
}

\author{
Maria Victoria González ${ }^{1}$ and Manuel Coque \\ Department of Fruticultura, I.E.P.A., Villaviciosa, 33300 Villaviciosa, Asturias, Spain \\ Maria Herrero \\ Unidad de Fruticultura, S.I.A.-D.G.A, Campus de Aula Dei, Apurtado 727, 50080 Zuragoza, Spain
}

Additional index words. Actinidia deliciosa, stigma, pollen, fruit set

\begin{abstract}
The effective pollination period was determined in kiwifruit [Actinidia deliciosa (Chev.) Liang and Fergusonl and the factors affecting it were evaluated. The effective pollination period, measured as the capability to set fruit after handpollinating flowers of different ages, was 4 days; 5 days after anthesis fruit set decreased and 2 days later it was nil. Pollen tube growth did not appear to he a limiting factor since pollen tubes grew quickly and reached the base of the style 2 days after pollination and reached the ovules 1 day later. Ovules appeared viable for the 7 days following anthesis, and visibly degenerated within the following 3 days. Stigmatic receptivity was determined by the ability to sustain pollen germination after hand pollinating flowers of different ages. The duration of stigmatic receptivity closely fit the effective pollination period determined through fruit set. Thus, it appears that stigma receptivity is the main factor responsible for the short effective pollination period.
\end{abstract}

Kiwifruit is a crop that is highly dependent on pollination since fruit weight is closely related to the number of seeds (Pyke and Alspach, 1986). Pollination, however, is impaired by thedioecious nature of the species. Whereas wind partially contributes to pollen transfer (Craig and Stewart, 1988), bee activity clearly increases fruit set (Clinch, 1984). The possibility of using artificial pollination has also been considered (Hopping and Hacking, 1983). Successful pollination, fertilization of the ovule, and fruit set depend upon receptivity of flowers during the few days following anthesis. In this context, it is crucial to identify the main factor limiting the effective pollination period (EPP) and its implications on crop yield. Williams (1965) introduced the concept of EPP and analyzed the effects of pollen tube growth rate, ovule longevity and the period of stigmatic receptivity in limiting EPP in apple. He found that, under the conditions of his experiment, the duration of the EPP was determined by the longevity of the ovule minus the time necessary for pollen tube growth. Although, Williams envisioned that, under more favorable temperature conditions, the receptive period of the stigmas would probably be an important factor determining the pollination period.

Whereas Williams' work was done on apple, EPP has also been associated with difficulties in fruit set in other species such as pear (Jaumien, 1968), prunes (Thompson and Liu, 1973), and cherries (Stiisser and Anvari, 1982). These difficulties have been attributed to slow growth of pollen tubes in the style and/or a short viability of ovules (Egea et al., 1991). During these studies, the idea that stigmatic receptivity could also impair fruit set was supported by experimental evidence (Egea et al., 1991; Egea and Burgos, 1992; Herrero, 1983). In the present work the EPP has been determined in kiwifruit. Pollen tube growth, ovule development, and stigma receptivity were evaluated to elucidate the limiting factor for EPP.

Received forpublication 25 Apr. 1994. Accepted forpublication 22 Sept. 1994. We thank R. Sanchez Tames and R. Rodriguez from laboratory of plant physiology (Univ. of Oviedo, Spain) for letting us use the facilities of their laboratory, M. Ciordia for helping us with the meteorological data, and J. Molina for photographic assistance. We also thank INIA for providing a fellowship to M.V.G. Financial support came from projects INIA 9123 and 8559 and CICYT AGF 92-0739.The cost of publishing this paper was defrayed in part by the payment of page charges. Under postal regulations, this paper therefore must be hereby marked advertisement solely to indicate this fact.

${ }^{1}$ To whom reprint requests should be addressed.

\section{Materials and Methods}

Plant material. Eight-year-old vines of 'Hayward' grafted on 'Bruno' seedlings and grown in northern Spain were used in these experiments. Pollinations were performed with pollen from a male (male C) selected out of a population of seedlings for being a good pollinator under these conditions (Gonzalez et al., 1994). Pollen was obtained by collecting male flowers 1 day before anthesis, considering anthesis as the day the flower opens. Anthers were dried on paper at room temperature for $24 \mathrm{~h}$. The pollen was then sieved using a fine mesh $\left(0.26 \mathrm{~mm}^{2}\right)$ to remove dehisced anthers and other impurities. Female Rowers were isolated by bagging them 1 day before anthesis to prevent free pollination.

Effective pollination period. A procedure used by Williams (1970) was followed to evaluate the EPP. Twenty-five previously isolated flowers were hand-pollinated with the help of a camel brush at 1, 2, 3, 4, 5, 6, and 7 days after anthesis. Fruit set was recorded in these flowers 30 days after pollination. Data were analyzed using Duncan's multiple range test.

Pollen tube observations. Similarly isolated flowers were handpollinated at anthesis and observed by fluorescence and scanning microscopy to study pollen tube growth. Five hand-pollinated flowers were fixed daily in formaldehyde: acetic acid: $70 \%$ ethanol ( $1: 1: 18$; FAA) (Johansen, 1940) for the first 15 days after pollination. Pollen tube growth in the stigma and style was monitored by fluorescence light microscopy in squash preparations of the stigmatic arms according to Jefferies and Belcher (1974) and Linskens and Esser (1957). The fixative was washed out of the dissected stigmatic arms with distilled water. The tissue was softened by warming to the boiling point in $5 \% \quad \mathrm{SO}_{4} \mathrm{Na}_{2}$ and subsequently stained with $0.1 \%$ aniline blue in $0.1 \mathrm{~N} \mathrm{PO}_{4} \mathrm{~K}_{3}$. Pollen tube penetration was followed in isolated ovules using the same technique but softening was omitted. For scanning electron microscopy, five flowers per day were fixed at anthesis and for the next 5 days in 3\% glutaraldehyde in $25 \mathrm{mM}$ phosphate buffer ( $\mathrm{pH} 6.8$ ), dehydrated in an alcohol series $(50 \%, 75 \%, 95 \%$, and $100 \%$ ethanol), critical point dried using $\mathrm{CO}_{2}$ and coated with gold. Specimens were observed under a Philips P 500 scanning electron microscope.

Stigmatic receptivity. To evaluate stigmatic receptivity, flowers isolated just before anthesis were pollinated at different inter- 


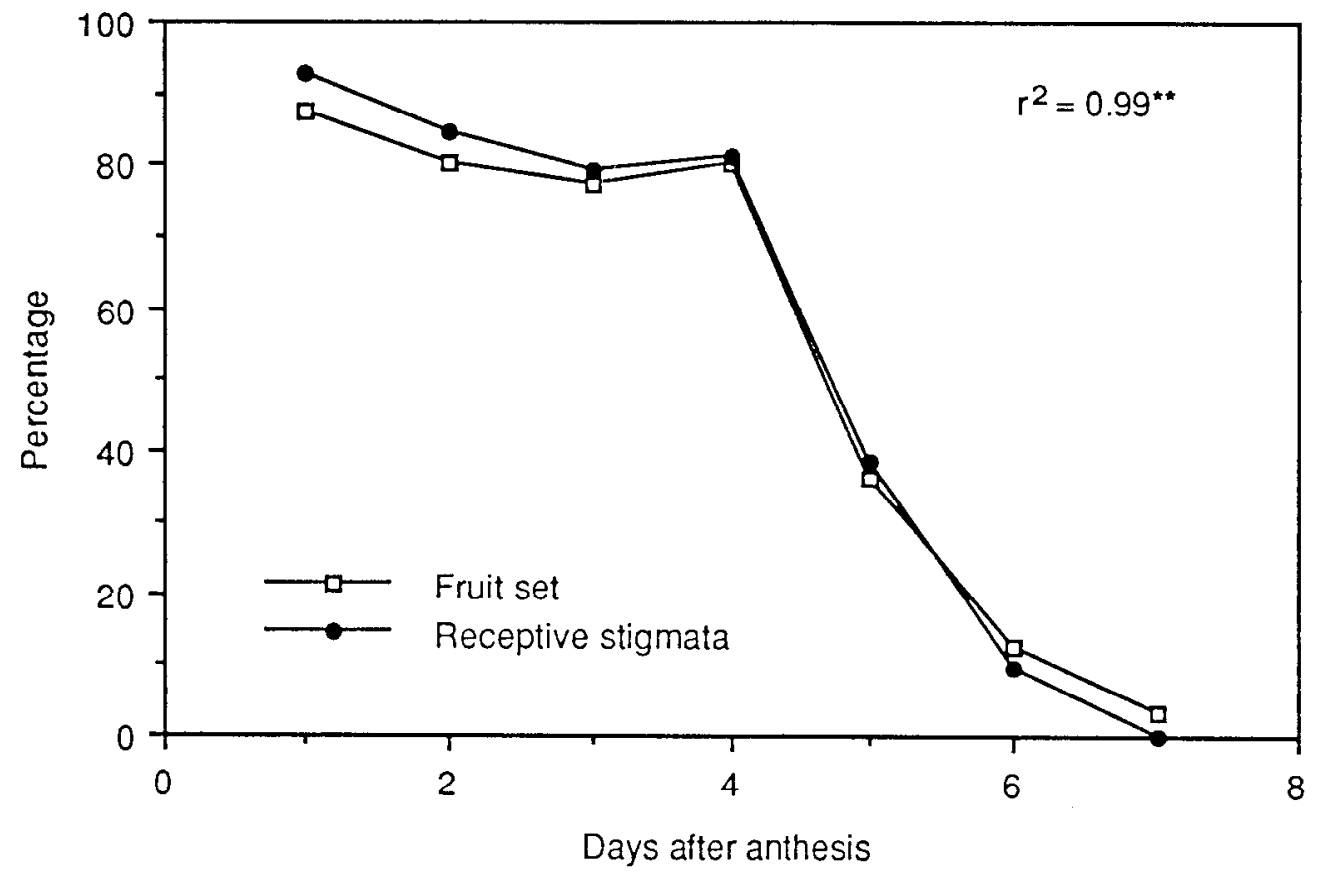

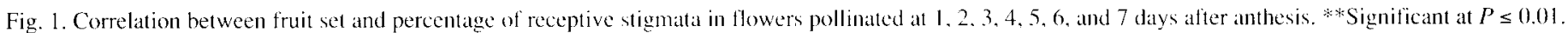

vals, as in the determination of the EPP, so that the flowers were $1,2,3,4,5,6$, or 7 days postanthesis at the time of pollination. One day after pollination, 10 flowers per day were fixed in FAA. The ability to sustain pollen germination was evaluated by sampling three stigmatic arms per day in each of these 10 flowers. and observing pollen germination on stigmas in squash preparations after aniline blue staining. Data were analyzed using Duncan's multiple range test.

Histological preprations. To evaluate ovule development, flowers were isolated just before anthesis; a group of them was pollinated at anthesis, and another group was left unpollinated. Ten pollinated and 10 unpollinated flowers were fixed daily in FAA during the first 15 days after anthesis and then embedded in paraffin wax after dehydration in a tertiary butyl alcohol series $(50 \%, 70 \%, 85 \%, 95 \%$, and 100\%). Sections $10 \mu \mathrm{m}$ thick were stained with $0.1 \%$ aniline blue to observe pollen tube growth and with safranin crystal violet and fast green according to Gerlach (1969). Ovule development was also observed in flowers fixed in $2.5 \%$ glutaraldehyde in $30 \mathrm{~mm}$ phosphate buffer ( $\mathrm{pH}$ 6.8). After gradual dehydration in a series of ethanol (70\% to $95 \%$ ethanol), the samples were embedded in Historesin (Reichert-Jung) and cut into $2-\mu \mathrm{m}$ sections, which were stained with PAS $(0.5 \%$ periodic acid-Schiff reactive) followed by $0.02 \%$ toluidine blue at $60 \mathrm{C}$ for $30 \mathrm{sec}$ (modified from Feder and O'Brien, 1968).

\section{Results}

Determination of the EPP. Fruit set after hand pollination was high, averaging $80 \%$ during the first 4 days following anthesis. However, when the flowers were pollinated 5 days after anthesis, fruit set decreased to $36 \%(P \leq 0.05)$. By 7 days after anthesis fruit set was practically nil. Thus, the EPP was limited to the first 4 days after anthesis (Fig. 1).

Pollen tube and ovule development. Pollen grains germinated (Fig. 2A) and pollen tubes reached the stylar transmitting tissue 1 day after pollination. One day later they grew to the base of the style (Fig. 2B) and 3 days after pollination the first fertilized ovules could be seen (Fig. 2C). Upon the arrival of the pollen tubes, the embryo sacs appeared mature with an egg ceil. two synergids, and one or two polar nuclei (Fig. 2D). In unpollinated flowers, the ovules showed no apparent signs of degeneration 7 days after anthesis (Fig. 2E). Four days later, however. ovules appeared degenerated (Fig. 2F) as manifested by empty or disorganized embryo sacs and by the shrunken appearance of nucellus and integuments.

Stigmatic receptivity. During the first 4 days that followed anthesis, stigmatic receptivity averaged $84 \%$ and sharply decreased to nil after 7 days. When data from stigmatic receptivity were plotted with those of fruit set, the two curves had a close fit (Fig. 1) $\left(r^{2}=0.99\right)$.

\section{Discussion}

The EPP in kiwifruit appears to be 4 days and appears to be limited by stigmatic receptivity. The pollen tube growth rate does not appear to be responsible to this short EPP, since the pollen tubes proceed expeditiously in this species. This may be due to an optimal temperature for pollen tube growth occurring during the kiwifruit flowering period (15C as mean temperature and $20 \mathrm{C}$ as mean maximum temperature), since temperature has a clear effect on pollen tube growth (Williams, 1970)

Embryo sac viability has been responsible for limited EPP in a number of instances (Thompson and Liu, 1973; Stösser and Anvari, 1982: Burgos and Egea, 1993). This situation, while having a genetic component with cultivars that are more prone than others to have a reduced ovule viability (Jaumien, 1968). is also clearly affected by the nutritive state of the tree. Thus, Williams (1965) recorded an increase in the EPP in 'Cox's Orange Pippin' apple associated with a prolonged viability of the embryo sacs in flowers sprayed with nitrogen the previous year. A similar situation has been described in 'Comice' pear, for which a putrescine spray increased fruit set due to a prolonged embryo sac viability (Crisocto et al.. 1988). In kiwifruit, ovules show no anatomical signs of degeneration by 7 days after anthesis and degeneration of 


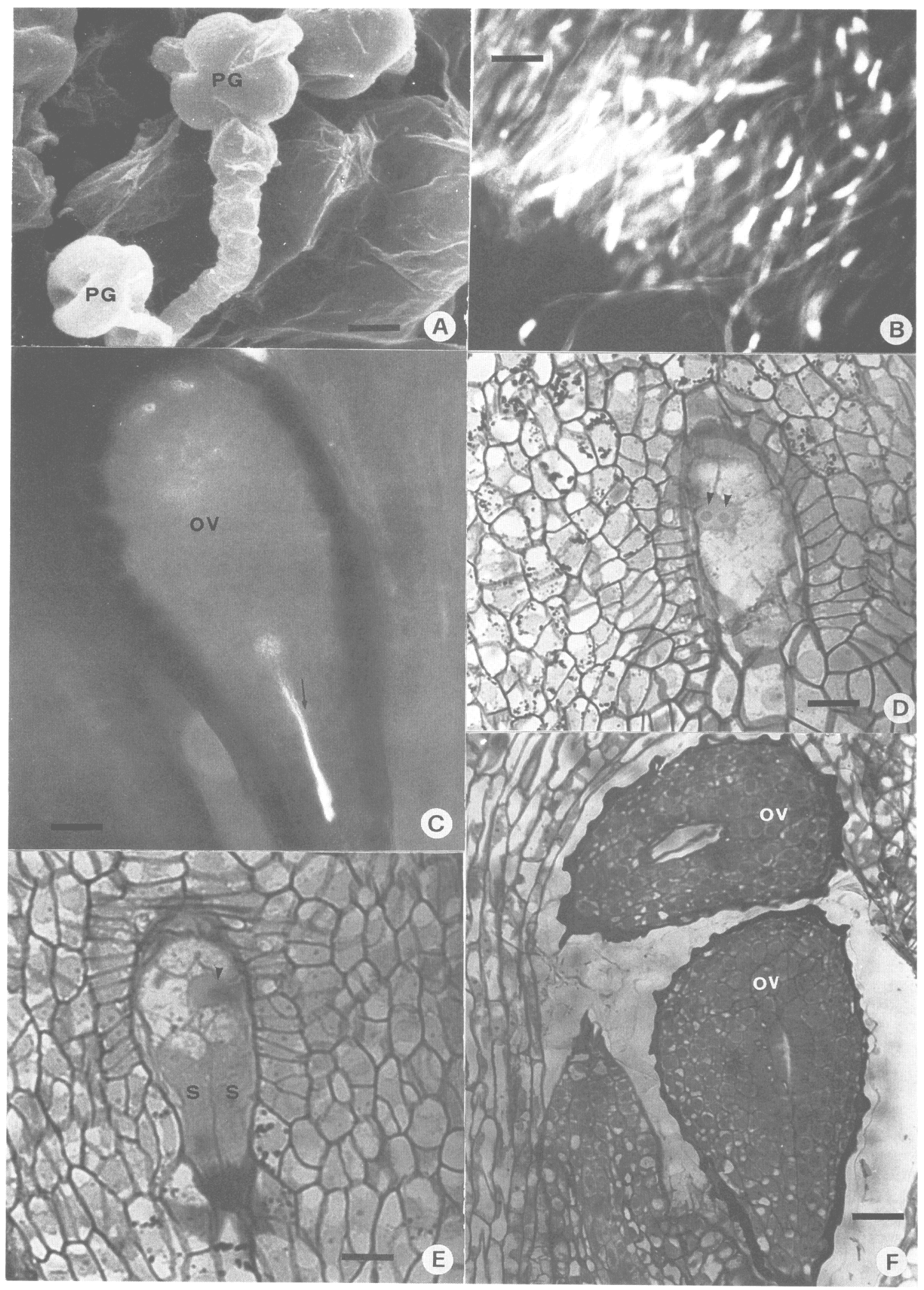

Fig. 2. Pollen tube and ovule development. (A) Germinated pollen grains (PG) on the stigma 1 day after pollination. Scanning electron microscopy. Bar $=6 \mu$ m. $($ B) Pollen tubes at the base of the style 2 days after pollination. Aniline blue stained squash preparations. Bar $=20 \mu \mathrm{m}$. (C) Pollen tube (arrow) penetrating an ovule (ov) 3 days after pollination. Aniline blue stained $10 \mu \mathrm{m}$ paraffin sections. Bar $=125 \mu \mathrm{m}$. (D) Mature embryo sac of an unpollinated flower3 days after anthesis, two polar nuclei (arrowheads) are apparent. PAS -Toluidine blue stained 2- $\mu \mathrm{m}$ Historesin sections. Bar $=50 \mu \mathrm{m}$. (E) Undegenerated embryo sac of an unpollinated flower 7 days after anthesis, two conspicuous synergids (s) and one polar nucleus (arrowhead) are apparent. PAS -Toluidinc blue stained 2- $\mu \mathrm{m}$ Historesin sections. Bar $=50 \mu \mathrm{m}$. (F) Twodegenerated ovules (ov) of an unpollinated flower 11 days after anthesis. PAS -Toluidine blue stained 2- $\mu \mathrm{m}$ Historesin sections. Bar $=125 \mu \mathrm{m}$. 
the stigma precedes that of the ovule. This may be related to the fact that, as in other species, maturation occurs in a basipetal way starting at the stigma and finishing at the ovary (Dickinson et al., 1982; Herrero and Arbeloa, 1989).

The close fit between the pattern of fruit set and that of stigmatic receptivity in kiwifruit indicates that EPP is limited by stigmatic receptivity. The stigma is receptive only during the first few days after anthesis. In fact, in this species the whole pistil appears to be ready for the reproductive process at flower opening and this readiness has been interpreted as being responsible for its high reproductive success (González et al., 1995a). Limited stigmatic receptivity at anthesis has been shown to impair fruit set during the short EPP of pear (Herrero, 1983) and apricot cultivars (Egea et al., 1991). The situation reported here in kiwifruit closely resembles the one described for apricot, perhaps due to high temperatures at flowering.

The question of what makes the stigma receptive to pollen remains open. The onset of stigmatic receptivity appears to be associated with the production of stigmatic secretion that provides an adequate medium to sustain pollen germination (Herrero and Dickinson, 1981). It also appears to be associated with esterase (Matson et al., 1974; Bernhardt et al., 1980) and peroxidase (Galen and plow right, 1987) activities; however, little work has been done to determine what makes a stigma unreceptive. In kiwifruit, loss of pollen germinability on the stigma may be due to the loss of stigmatic papillar cell integrity, which may cause release of cellular contents into the stigmatic exudate, in turn altering the medium and preventing pollen germination (González et al., 1995b).

This work shows a short EPP for 'Hayward'. A similar situation has been recorded under different cultural conditions (Galimberti et al., 1987, 1988). indicating that it may be a general feature of this cultivar. From an agricultural standpoint, the time of pollination effectiveness is much reduced and any weather alteration impairing pollination can have a major effect on the final crop. The duration of stigmatic receptivity closely fits the effective pollination period, determined through fruit set. Thus, it appears that stigma receptivity is the main factor responsible for this short effective pollination period.

\section{Literature Cited}

Bernhardt, P., R.B. Knox and D.M. Calder. 1980. Floral biology and selfincompatibility in some Australian mistletoes of the genus Amyema (Loranthaceae). Austral. J. Bot. 28:437-451.

Burgos, L. and J. Egea. 1993. Apricot embryo-sac development in relation to fruit set. J. Hort. Sci. 68:203-208.

Clinch, P.G. 1984. Kiwifruit pollination by honey bees I. Tauranga observation 1978-81. N.Z. J. Expt. Agr. 12:29-38.

Craig, J.L. and A.M. Stewart. 1988. A review of kiwifruit pollination: where to next?. N.Z. J. Expt. Agr. 16:385-399.

Crisosto. C.H., P.B. Lom bard, D. Sugar, and V.S. Polito. 1988. Putrescine influences ovule senescence, fertilization time, and fruit set in 'Cornice' pear. J. Amer. Soc. Hort. Sci. 113:708-712.

Dickinson, H.G., J. Moriarty, and J. Lawson. 1982. Pollen-pistil interaction in Lilium longiflorum: the role of the pistil in controlling pollen tube growth following cross and self pollination. Proc. Royal Soc. London B
215:45-62.

Egea, J., L. Burgos, J.E. Garcia, and L. Egea. 1991. Stigma receptivity and style performance in several apricot cultivars. J. Hort. Sci. 66: 19-25.

Egea, J. and L. Burgos. 1992. Effective pollination period as related to stigma receptivity in apricot. Sci. Hort. 52:77-83.

Feder, N. and T.P. O'Brien. 1968. Plant microtechnique: some principles and new methods. Amer. J. Bot. 43: 11-22.

Galen, C. and R.C. Plowright. 1987. Testing the accuracy of using peroxidase activity to indicate stigma receptivity. Can. J. Bot. 65: 107111.

Galimberti, P., M. Marro, and J. Youssef. 1987. Periodo utile d'impollinazione in Actinidia chinensis (Planch). Riv. Frutticoltura 49:51-54.

Galimberti, P., M. Marro, and J. Youssef. 1988. Periodo utile d'impollinazione in Actinidia deliciosa. II. Contributo. Riv. Frutticoltura 50:71-74.

Gerlach, D. 1969. A rapid safranin-crystal violet-light green staining sequence For paraffin sections of plant materials. Stain Technol. 44:210211.

González, M.V.. M. Coque, and M. Herrero. 1994. Pollinator selection in kiwifruit (Actinidia deliciosa). J. Hort. Sci. 69:697-702.

González, M.V., M. Coque, and M. Herrero. 1995a. Pollin-pistil interaction in kiwifruit (Actinidia deliciosa: Actinidiaceae). Amer. J. Bot. (In press.)

González, M.V., M. Coque, and M. Herrero. 1995b. Papillar integrity as an indicator of stigmatic receptivity in kiwifruit (Actinidia deliciosa). J. Expt. Bot. (In press.)

Herrero, M. 1983. Factors affecting fruit set in 'Agua de Aranjuez' pear. Acta Hort. 139:91-96.

Herrero, M. and A. Arbeloa. 1989. Influence of the pistil on the pollen tube kinetics in peach (Prunus persica). Amer. J. Bot. 76:1441-1447.

Herrero, M. and H.G. Dickinson. 198 1. Ultrastructural and physiological differences between buds and mature flowers of Petunia hybrida prior to and following pollination. Planta 148:138-145.

Hopping, M.E. and N.J.A. Hacking. 1983. A comparison of pollen application methods for the artificial pollination of kiwifruit. Acta Hort. 139:41-50.

Jaumien, F. 1968. The causes of poor bearing of pear trees of the variety 'Doyenne du Comice'. Acta Agrobot. 21:75-106.

Jefferies, C.J. and A.R. Belcher. 1974. A fluorescent brightener used for pollen tube identification in vivo. Stain Technol. 49:99-202.

Johansen, D.A. 1940. Plant Microtechnique. McGraw-Hill. New York. Linskens, H.F. and K. Esser. 1957. Uber eine spezifische anfärbung der pollenschläuche und die zahl kallosaproplen nach selbstung und fremdung. Natturwissenchaften 44:16.

Matson, O., R.B. Knox, J. Heslop-Harrison, and Y. Heslop-Harrison. 1974. Protein pellicle of stigmatic papillae as a possible recognition site in incompatibility reactions. Nature 247:298-300.

Pyke, N.B. and P.A. Alspach. 1986. Inter-relations on the pollination of Chinese gooseberries variety 'Hayward'. N. Z. J. Exper. Agric. 2:455458.

Stösser, R. and S.F. Anvari. 1982. On the senescence of ovules in cherries. Sci. Hort. 16:29-38.

Thompson, M.M. and I.J. Liu. 1973. Temperature. fruit set and embryo sacdevelopment in 'Italian' prune. J. Amer. Soc. Hort. Sci. 98:193-197.

Williams, R.R. 1965. The effect of summer nitrogen applications on the quality of apple blossom. J. Hort. Sci. 40:31-41

Williams, R.R. 1970. Techniques used in fruit set experiments, p. 57-61 In: R.R. Williams and D. Wilson (eds.). Towards regulated cropping. Grower Books, London. 